\title{
Biosynthesis and Characterization of Ag Nanoparticles Using the Equisetum hyemale L. Plant Extract.
}

\author{
Gabriela Gonzalez, Gerardo Rosas and Salomon Borjas
}

Universidad Michoacana de San Nicolás de Hidalgo, Morelia, Michoacan de Ocampo, Mexico,

Recently, the synthesis of silver nanoparticles (Nps) has been of great interest due to their optical, chemical and catalytic properties, which depend on their shape, size and chemical composition [1]. However, to take advantage of its biomedical properties, it is necessary to use synthetic methods free of toxic chemicals. For this reason, green methods have been developed that consist of using plant extracts that contain active substances such as reducing agents and stabilizing agents [2].

The extract was prepared in $50 \mathrm{ml}$ of distilled water, 1, 1.5, 2, 2.5, 3 and $4 \mathrm{~g}$ of the plant were added; the water was heated to its boiling point afterwards the plant was added and left under continuous stirring for $30 \mathrm{~min}$. $\mathrm{AgNO}_{3}$ was used as a precursor salt at a concentration of $8 \mathrm{mM}$. Once the extract was previously filtered and at room temperature $\mathrm{AgNO}_{3}$ was added, the bottles were covered with aluminum foil to avoid the influence of light on the synthesis.

In the annex to figure 1a shows a color change from transparent to dark brown which happened at 60 minutes of reaction, this change in color has already been reported in multiple investigations [3], which indicate the successful obtaining of Ag Nps. Using the ultraviolet-visible spectroscopy technique (Figure 1a), we can be seen a well-defined surface plasmon peak at $430 \mathrm{~nm}$ with $1 \mathrm{~g}$ of Equisetum hyemale L indicating the presence of Ag Nps with a size distribution homogeneous, on the other hand there is no peak when the amount of plant present in the extract was greater than $1 \mathrm{~g}$. These results were observed by scanning electron microscopy (SEM) for $1 \mathrm{~g}$ (figure 1b), $2 \mathrm{~g}$ (figure 1c) and $4 \mathrm{~g}$ (figure 1d), where you can see a large density of formed Nps of Ag, which They are well dispersed, however, as the amount of the plant increased, the Nps are observed to be encapsulated in the organic substances of the plants, which is why the peak of plasmon is not seen in the UV spectrum -Previous view. Figure 1e shows the result of the chemical analysis by EDS of the sample synthesized with $1 \mathrm{~g}$, where the presence of Ag is observed.

On the other hand, Figure 2a shows a micrograph obtained from the transmission electron microscope (TEM) by the clear field technique of nanoparticles synthesized with $1 \mathrm{~g}$ of plant, in which it can be seen that they are well dispersed, of the histogram Annex shows that the Nps in general have a size smaller than $50 \mathrm{~nm}$ being in a range of 5-35 nm although the highest frequency of sizes was found in $20 \mathrm{~nm}$. These results are comparable with Gengan et al [4]. and Thirunavoukkarasu et al. [5] which used the plants Albizia adianthifolia and Desmodium gangeticum L, respectively. Figure 2 shows a series of high resolution transmission electron microscopy (HRTEM) images, where various sizes and shapes of Ag nanoparticles obtained can be seen. For example, it is observed as to how this can be faceted (b), spherical (c), ellipsoidal (d), pseudo-hexagonal (e), and elongated (f). A general characteristic in all of them is their polycrystallinity which is more marked in this case in the ellipsoidal particle, which has a polynuclear growth that is a consequence of a high aggregation speed, which suggests that they grew rapidly although the reagents were depleted at same speed generating growth through the Ostwald ripening mechanism. Finally, the FFT pattern of one of the particles having a completely hexagonal structure is appreciated, where the inter-planar distances correspond to $0.23 \mathrm{~nm}$ that belong to the planes (111) of the same cubic silver structure.

We can be concluded that Ag nanoparticles were successfully obtained, with $1 \mathrm{~g}$ of Equisetumm hymale $L$ in the extract and $8 \mathrm{mM}$ of $\mathrm{AgNO}_{3}$. 

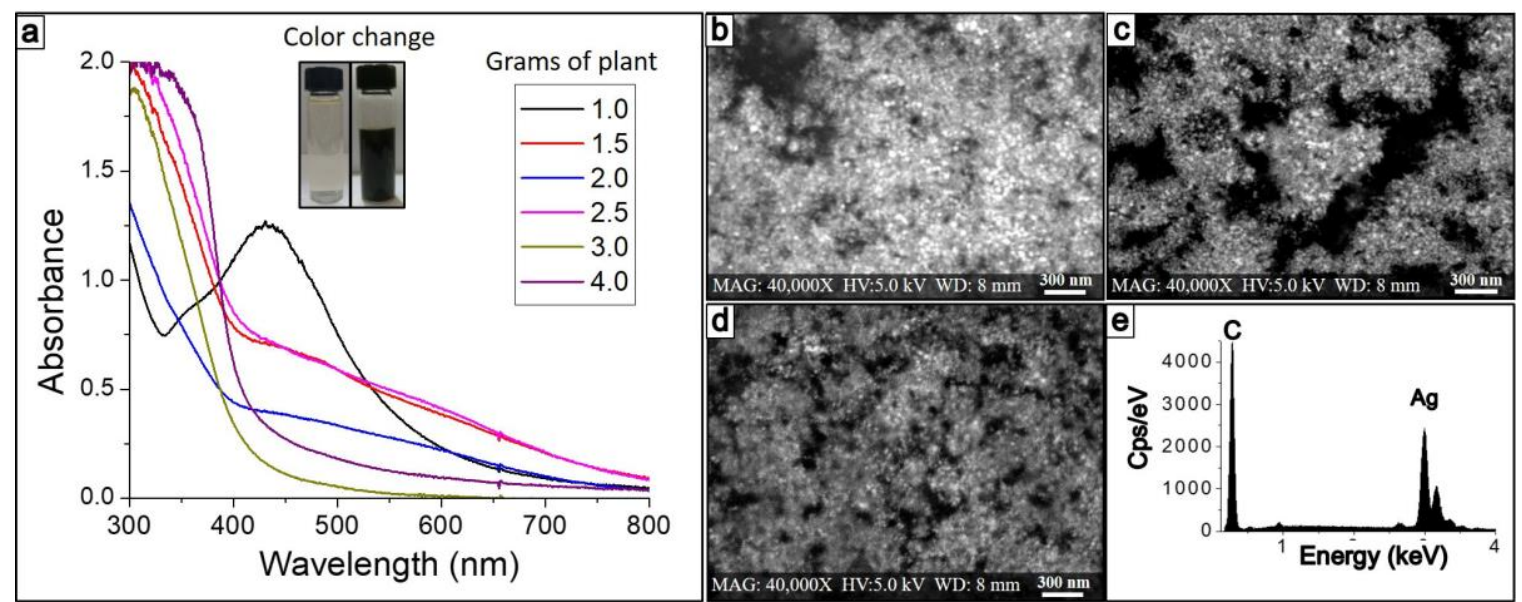

Figure 1. a) Uv-vis spectra of Ag nanoparticles, b-d) SEM images with 1,2 and $4 \mathrm{~g}$ of plant and e) EDS pattern.

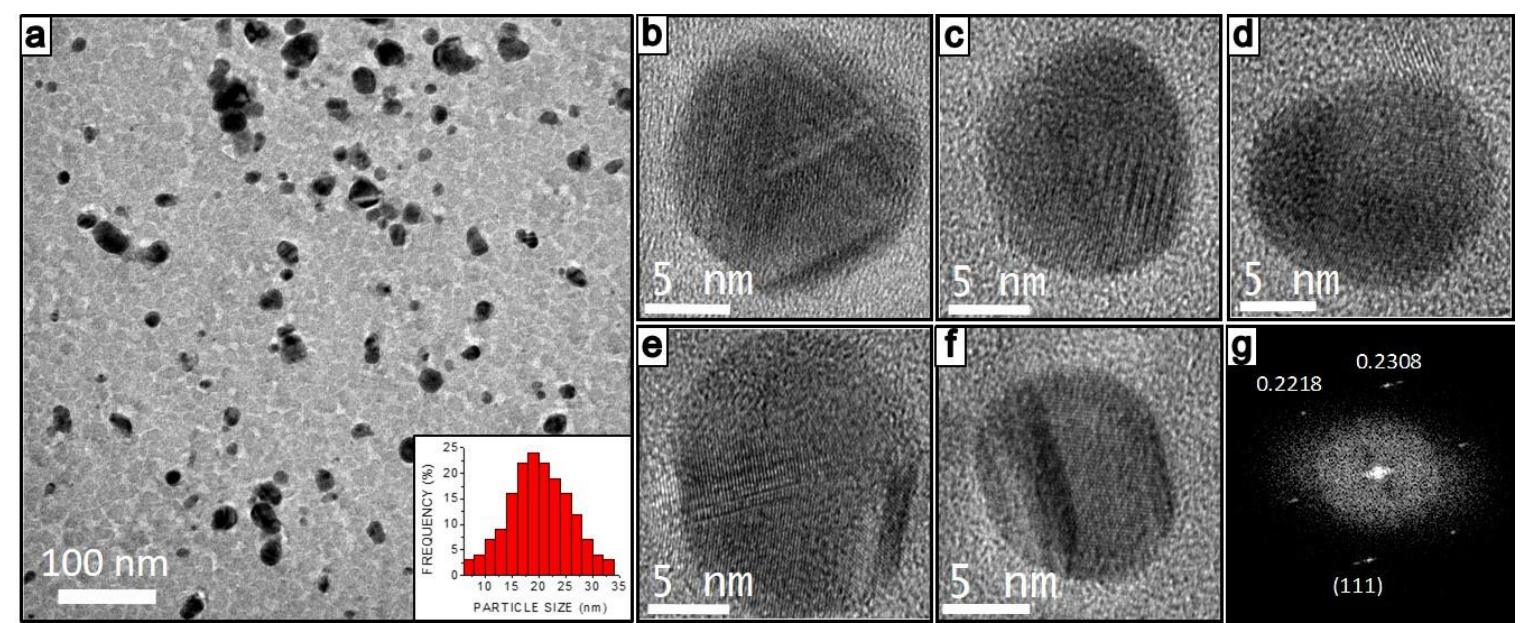

Figure 2. TEM images and size distribution a) bright field, b-f) HRTEM of Ag Nps and g) FFT pattern of $\mathrm{Np}$.

\section{References}

1. Khan, I., K. Saeed, and I. Khan, Nanoparticles: Properties, applications and toxicities. Arabian Journal of Chemistry, 2019. 12(7): p. 908-931.

2. Rafique, M., et al., A review on green synthesis of silver nanoparticles and their applications. Artificial Cells, Nanomedicine, and Biotechnology, 2017. 45(7): p. 1272-1291.

3. Gonzalez, A., et al., Size, Shape, Stability, and Color of Plasmonic Silver Nanoparticles. The Journal of Physical Chemistry C, 2014. 118: p. 9128-9136.

4. Gengan, R.M., et al., A549 lung cell line activity of biosynthesized silver nanoparticles using Albizia adianthifolia leaf. Colloids and Surfaces B: Biointerfaces, 2013. 105: p. 87-91.

5. Thirunavoukkarasu, M., et al., Biosynthesis of silver nanoparticle from leaf extract of Desmodium gangeticum (L.) DC. and its biomedical potential. Spectrochimica Acta Part A: Molecular and Biomolecular Spectroscopy, 2013. 116: p. 424-427. 